\title{
Optic nerve glioma and phaeochromocytoma associated with von Recklinghausen's disease: A case report
}

\author{
HANS FLEDELIUS AND POUL ELDRUP-JØRGENSEN \\ From the Eye Pathology Institute, University of Copenhagen, Denmark, and the Institute of Pathology, \\ Randers Centralsygehus, Randers, Denmark
}

SUMMARY A 32-year-old woman who died suddenly during pregnancy as a result of an adrenal phaeochromocytoma also suffered from von Recklinghausen's disease. 21 years earlier she had an optic nerve glioma successfully removed. The association between von Recklinghausen's disease and optic nerve glioma/phaeochromocytoma is well established. So far as is known, the present case is the first ever published with the triad: von Recklinghausen's disease, optic nerve glioma, and phaeochromocytoma.

During a follow-up study concerning orbital tumours in childhood (Eldrup-Jørgensen and Fledelius, 1975), we became acquainted with the story of a female who died during pregnancy 21 years after successful removal of an optic nerve glioma. The patient further suffered from von Recklinghausen's disease and died as a result of an adrenal phaeochromocytoma. To our knowledge this clinical triad has not been previously reported.

\section{Case report}

In 1964 a 32-year-old pregnant woman was admitted to hospital as an emergency case. After a few hours at home with pain in chest and shoulders she became comatose. Cardiac arrest soon followed, and resuscitation efforts, continued in hospital, were ineffective. At necropsy a large adrenal phaeochromocytoma with a central haemorrhage was found (Fig. 1a).

She had experienced throughout her life frequent periods of illness, and been admitted many times (about 20) to various hospitals. In the following account her history is arranged according to symptom groups rather than to chronology.

Von Recklinghausen's disease. The patient's mother and two brothers had café-au-lait spots. Since birth, the patient had had a soft swelling at the left angle of the mouth, which was regarded as primarily a lymph- or haemangioma. During 193943 , when she was 7 to 11 years old, she received

Address for reprints: Eye Pathology Institute, Rigshospitalet, 9 Blegdamsvej, DK-2100 Copenhagen Ø, Denmark radiotherapy, without effect. During 1948-55 repeated excisions and plastic repair were carried out. Histopathological examination of removed tissue showed neurofibroma. Café-au-lait spots and cutaneous nodules (some of which were pigmented) occurred all over the trunk and limbs, increasing in number with age.

Optic nerve glioma. At the age of 10 she developed protrusion and blindness of the left eye (the right eye remained unaffected throughout life). In 1943 a thickened orbital part of left optic nerve was excised (Krönlein procedure). The pathological report stated it was an optic nerve glioma (oligodendroglioma); signed Erna Christensen, Eye Path. Lab. No. 51/43 (Fig. 1b). In the following 21 years there were no signs of local recurrence.

Other neurological symptoms. A brother died at 9 of epilepsy. Since 1954 (aged 22) the patient had had epileptiform attacks (grand-mal type). She was twice examined in a neurological department (1955 and 1962) without findings indicating intracranial tumour or other focal lesion. Treatment was with phenytoine and mysoline. In 1954 she had a head injury with concussion. Since then she has had bifrontal headache almost daily, sometimes with prodromal hemicraniform visual disturbances.

Abdominal symptoms. Since her first pregnancy in 1953 (normal delivery of a normal girl) she has had repeated 'biliary colic', without, however, laboratory or $x$-ray confirmation. Her body weight has always been low (about $44 \mathrm{~kg}$, height $158 \mathrm{~cm}$ ), sometimes with periods of weight loss. In 1960 an explorative laparotomy disclosed nothing abnormal except small cystic ovaries. 


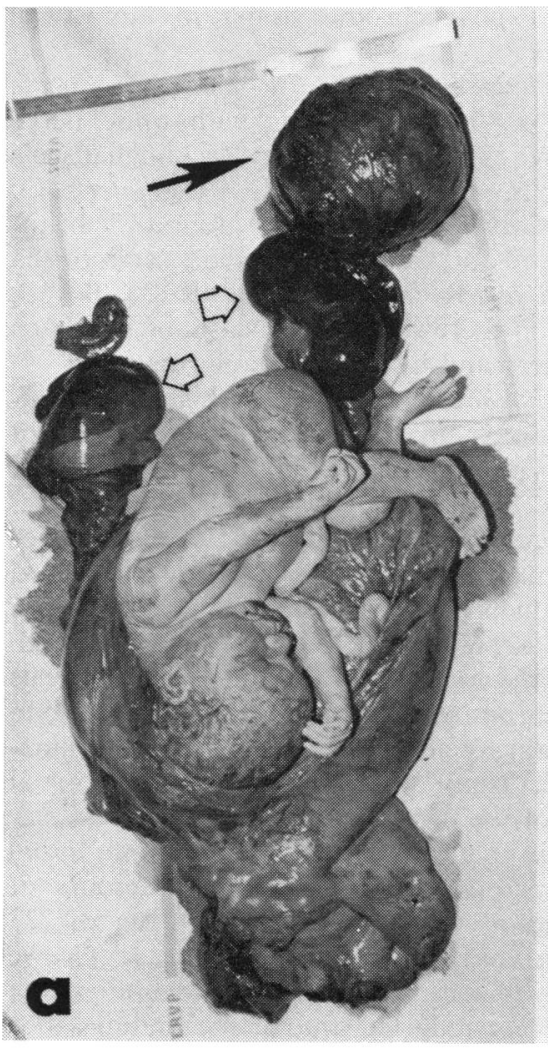

Symptoms or findings consistent with a hormonereleasing phaeochromocytoma. No real proof is available because her urine was never examined for vanillyl mandelic acid (VMA) and catecholamines, but the following (possibly related) symptoms appeared: from 1962 frequent episodes of shaking, and sometimes also dizziness and vomiting; later, attacks of palpitations and profuse sweating. Among the findings importance can be attached only to the blood pressure readings recorded during the various admissions to hospital. All were normal except for slight elevations on three occasions: $1960,180 \mathrm{mmHg}$ systolic during anaesthesia and laparotomy; 1962, 140/100 $\mathrm{mmHg}$ in the neurological department; 1964, 150/90 mmHg when admitted for imminent abortion in the second month of her last pregnancy.

\section{Necropsy (J. V. Thorborg)}

The main finding was an adrenal tumour (Fig. 1a,c). At the site of the left adrenal gland an encapsulated mass $(14 \times 13 \times 12 \mathrm{~cm}$, weight $300 \mathrm{~g})$ was easily detached from the kidney and other surrounding tissue. On the cut surface a thick peripheral rim of greyish-red solid tumour tissue was observed around a central irregularly torn cavity filled with partly coagulated blood, escaping under pressure when cut. Remnants of the right adrenal gland could be discerned as a $2 \cdot 5-\mathrm{cm}-$ long slightly prominent ridge on the surface of the tumour.

Histopathology. The sparsely vascularised tumour tissue (Fig. 1c) consisted of massive aggregates of fairly uniform cells with rounded or polyhedral nuclei and abundant, slightly granular cytoplasm. Mitoses were not observed. The overall impression from the nuclear morphology was that of a benign tumour. There were some sinusoids and irregular spaces between the cell cords. Chromaffin granules within the tumour cells could not be demonstrated (potassium dichromate stain), probably because of the lapse of time ( 23 hours) between death and tissue fixation. The diagnosis was phaeochromocytoma with haemorrhage.

Other relevant findings. (a) Positive: The heart $(300 \mathrm{~g})$ showed a slight hypertrophy of the left ventricular walls $(17 \mathrm{~mm}$ in thickness). The spleen was slightly enlarged $(500 \mathrm{~g})$. The uterus contained a female fetus ( $c f$. Fig. 1a), developed according to the duration of the pregnancy and without deformi- 
ties. (b) Negative: The right adrenal gland and the thyroid and parathyroid glands were normal. There were no focal lesions in brain or brain stem, and in particular no tumours, aneurysms, or other vascular malformations.

\section{Discussion}

In this rather mixed clinical picture von Recklinghausen's disease must be considered the basic disorder. This disease is known to involve potentially every part of the central and peripheral nervous systems (Crowe et al., 1956), and the symptomatology varies accordingly. Von Recklinghausen's disease is one of the so-called phakomatoses or neurocutaneous syndromes (the other clinical entities usually included being von Hippel-Lindau disease, tuberous sclerosis, and Sturge-Weber's syndrome), a group of often heredofamilial disorders. It is confined to neuroectodermally derived structures, and the additional finding of phaeochromocytomas in some of these patients is not surprising for they develop from neural crest derived tissue (Chapman et al., 1959; Russel and Rubinstein, 1971). To give an idea of the associations of the different disorders in this field the following points from the literature are given in brief (we disregard here the association with thyroid and parathyroid tumours as well as other possible 'neurocristopathies'-cf. Bolande, 1974):

Von Recklinghausen's disease. The incidence among the general population is estimated at 1 per 2000 to 3000 (Marshall, 1954; Crowe et al., 1956).

Optic nerve glioma. The incidence of this tumour, mostly confined to childhood, is not given in the textbooks on the subject. Danish material suggests an incidence of about 1 per 100000 of the population (Christensen and Andersen, 1952; EldrupJørgensen and Fledelius, 1975).

Phaeochromocytoma. The frequency is estimated at 0.05 to $0.1 \%$ among the general population, but higher $(1 \%)$ in selected samples with hypertension (Melmon, 1968; Hansen, 1975).

Phaeochromocytoma and pregnancy. Blair (1963) reviewed 51 cases. Almost half of the women died from the tumour, which was named 'the great mimic', invariably leading to suspicion of pre-eclamptic toxaemia. It appears that the stress of pregnancy and/or the mechanical changes caused by the enlarged uterus may act as a trigger for a preexisting, previously silent phaeochromocytoma. The same conclusions arose from a more recent review (Schenker and Chowers, 1971) comprising 89 cases; in $39 \%$ the phaeochromocytoma was diagnosed only at post-mortem examination. In retrospect, however, there had been recognisable clinical symptoms of phaeochromocytoma in almost all these cases.

Von Recklinghausen's disease and optic nerve glioma. 10 to $40 \%$ of patients with optic nerve glioma show evidence of von Recklinghausen's disease (Davis, 1940; Marshall, 1954 inter al.). Conversely Crowe et al. (1956) found 2 histologically proved optic nerve gliomas in a series of 223 patients with von Recklinghausen's disease $(0.9 \%)$, but in addition there were several cases of blindness without surgery and histological confirmation.

Von Recklinghausen's disease and phaeochromocytoma. Neurofibromatosis is seen in 4 to $20 \%$ of patients with phaeochromocytoma (Glushien et al., 1953; Crowe et al., 1956; Barbeau, 1957; Hume, 1960). Conversely, however, only 1 case of phaeochromocytoma occurred in the above-mentioned series of 223 neurofibromatosis cases (Crowe et al., 1956). This apparent discrepancy was explained, according to the authors, "by the fact that individuals with phaeochromocytoma may well be rarer than those exhibiting neurofibromatosis'. This explanation, however, is not consistent with the fairly equal frequencies of the diseases cited above.

Associations between phaeochromocytoma, brain tumours, and neurocutaneous disease. Tumours of brain and brain stem were found in 6 out of 223 patients with von Recklinghausen's disease (Crowe et al., 1956). Phaeochromocytoma and optic nerve glioma were not reported among the findings in a review of 49 cases of von Recklinghausen's disease with acoustic neurinomas and multiple meningiomas (Rodriguez and Berthrong, 1966). Brain tumours in patients with von Recklinghausen's disease and phaeochromocytoma were reported by Barnard and Lang (1964) (disseminated astrocytic gliomas in brain and brain stem) and by Roberts (1967) (cerebral gliosarcoma). The coincidence of phaeochromocytoma and intracranial haemangioma (in a woman, and later also in her son) was reported by Chapman et al. (1959), by Chapman and Diaz-Perez (1962), and by Mulholland et al. (1969), but there was no cutaneous evidence of neurofibromatosis. Glushien et al. (1953) and Vilhelmsen and Fischer (1973) published cases (3 and 1, respectively) of phaeochromocytoma associated with Lindau's disease (intracranial haemangiomas, predominantly cerebellar).

So far as is known the present is the first published case with the clinical triad of von Recklinghausen's disease, optic nerve glioma, and phaeochromocytoma. As an additional point, it may be added that the adrenal tumour caused the patient's death during pregnancy. Furthermore, the prevailing neurological symptoms (epilepsy, headache, etc.) might have been caused by intracranial manifestations of von 
Recklinghausen's (or Lindau's) disease. The examinations performed (PEG, repeated EEG's) did not, however, reveal focal pathology, and lesions could not be demonstrated at brain necropsy. Her epilepsy should therefore be considered as heredofamilial and/or part of a post-concussion syndrome.

Earlier reports of sudden death due to massive haemorrhage into adrenal phaeochromocytomas (Lehman and Rosof, 1956; Huston and Stewart, 1965) emphasised abdominal pain and a state of shock as prevalent features. These also occurred in our patient, who did not die in a state of hypertension as is usually seen in lethal phaeochromocytomas. In relation to our patient the case of Lehman and Rosof (1956) was of further interest because of the necropsy finding of ' $a$ small meningioma in the area of the optic chiasm'. There was, however, no (other?) evidence of von Recklinghausen's disease.

The special interest of the present case is the coincidence of an inter-relationship between von Recklinghausen's disease and phaeochromocytoma. With this in mind the vague and neurasthenic type of complaints of the patient might have led to a suspicion of a phaeochromocytoma as a possible cause of her symptoms in the last 2 years of life. It is not unusual for patients with phaeochromocytoma to be found normotensive for years and to have only slight symptoms. For example, Hermann and Mornex (1964) in a study of 507 reported phaeochromocytomas noted that $10 \%$ were clinically latent. In some of these the tumour was disclosed by the unexpectedly severe responses to usually harmless examination procedures or-as in our case -to pregnancy.

Except for early treatment of the optic nerve glioma ophthalmologists were concerned in the present case only as consultants. The lesson for ophthalmologists is that they should be alert for optic nerve tumours and orbital neurofibromata in patients with von Recklinghausen's disease, and also look carefully for vascular retinal lesions. Hypertensive angiopathy may point to phaeochromocy- toma, and retinal angiomas may be part of von Hippel-Lindau disease.

\section{References}

Barbeau, A. (1957). Union Médicale du Canada, 86, 1045.

Barnard, R. D., and Lang, E. R. (1964). Journal of Neurosurgery, 21, 506.

Blair, R. G. (1963). Journal of Obstetrics and Gynaecology of the British Commonwealth, 70, 110.

Bolande, R. P. (1974). Human Pathology, 5, 409.

Chapman, R. C., and Diaz-Perez, R. (1962). Journal of the American Medical Association, 182, 1014.

Chapman, R. C., Kemp, V. E., and Taliaferro, I. (1959). American Journal of Medicine, 26, 883.

Christensen, E., and Andersen, S. R. (1952). Acta Psychiatrica et Neurologica Scandinavica, 27, 5.

Crowe, F. W., Schull, W. J., and Neel, J. V. (1956). A Clinical, Pathological and Genetical Study of Multiple Neurofibromatosis. Thomas: Springfield, Illinois.

Davis, F. A. (1940). Archives of Ophthalmology, 23, 735 and 957.

Eldrup-Jørgensen, P., and Fledelius, H. (1975). Acta Ophthalmologica, 53, 887.

Glushien, A. S., Mansuy, M. M., and Littman, D. S. (1953). American Journal of Medicine, 14, 318.

Hansen, A. T. (1975). Medicinsk Kompendium, pp. 1305-10. Busck: Copenhagen.

Hermann, H., and Mornex, R. (1964). Human Tumours Secreting Catecholamines. Macmillan: New York.

Hume, D. M. (1960). American Journal of Surgery, 99, 458.

Huston, J. R., and Stewart, W. R. C. (1965). American Journal of Medicine, 39, 502.

Lehman, D. J., and Rosof, J. (1956). New England Journal of Medicine, 254, 474.

Marshall, D. (1954). American Journal of Ophthalmology, $37,15$.

Melmon, K. L. (1968). In Textbook of Endocrinology, pp. 379-403. Ed. R. H. Williams. Saunders: Philadelphia, London and New York.

Mulholland, S. G., Atuk, N. O., and Walzak, M. P. (1969). Journal of the American Medical Association, 207, 1709.

Roberts, A. H. (1967). British Journal of Surgery, 54, 78.

Rodriguez, H. A., and Berthrong, M. (1966). Archives of Neurology, 14, 467.

Russel, D. S., and Rubinstein, L. J. (1971). Pathology of Tumours of the Nervous System, pp. 31-43, 232, and 323-329. Arnold: London.

Schenker, J. G., and Chowers, I. (1971). Obstetrical and Gynecological Survey, 26, 739.

Vilhelmsen, G., and Fischer, S. (1973). Ugeskrift for Laeger, 135, 1752. 